\title{
Perancangan Mesin Penghancur Bonggol Jagung Untuk Pakan Ternak Sapi Dan Kambing Kapasitas 100 Kg/Jam
}

\author{
Nehemia Ratur Tarigan, Nurdiana*), Iswandi, Eswanto ${ }^{* *}$, \\ Mahyunis, supriadi. M.Kamil \\ Jurusan Teknik Mesin, Fakultas Teknologi Industri, Institut Teknologi Medan \\ Jl.Gedung Arca No 52 Medan, 20271 \\ *Email: nurdiana@itm.ac.id;**eswanto@itm.ac.id
}

\begin{abstract}
ABSTRAK
Mesin penghancur bonggol jagung yang direncanakan adalah berfungsi untuk menghancurka bonggol jagung kering menjadi partikel-partikel kecil yang berukuran $2 \mathrm{~mm}$ atau lebih kecil mengunakan mekanisme poros, pisau, bantalan, puli, dan motor disel sebagai pengerak. Dalam perecanaan mesin penghancur bonggol jagung kapasitas yang direncanakan adalah 100 $\mathrm{kg} / \mathrm{jam}$. Dengan maksud memanfaatkan bonggol jagung menjadi pakan tambahan untuk pakan ternak sapi dan kambing dengan proses yang yang cepat.Pada rancangan penghancur bonggol jagung memiliki konstruksi utama yang terdiri dari mekanisme penghancuran bonggol jagung yang bekerja secara rotary dengan mengunakan poros yang terbuat dari bahan S35S-D dengan panjang $510 \mathrm{~mm}$, diameter $50 \mathrm{~mm}$ dan pisau penghancur yang terbuat dari bahan S35C dengan ukuran panjang $100 \mathrm{~mm}$, tebal pisau $5 \mathrm{~mm}$, gaya pnghancur bonggol jagung $108 \mathrm{~kg}$ dan mekanisme pengerak digunakan motor disel dengan putaran poros pengerak sebesar $2000 \mathrm{rpm}$. Sedangkan daya motor yang direncanakan untuk mengerakkan prangkat mesin penghancur bonggol jagung sebesar 16 Pk. Dari hasil perhitungan didapat daya total untuk motor pengerak sebesar 10,2kw dan untuk keamanan digunakan motor disel direncanakan adalah 11,936 kw $=16 \mathrm{Pk}$ dengan putaran $2000 \mathrm{rpm}$.Dari hasil yang diperoleh dapat disimpulkan bahwa dalam merancang mesin perancang dapat menentukan komponen yang sesuai untuk digunakan dalam mesin penghancur bonggol jagung dan dapat melakukan perhitungan setiap komponen.
\end{abstract}

Kata kunci: bonggol jagung, pakan ternak, ternak sapi dan kambing

Design Of Corn Cutters For Cattle And Goat Feed Capacity Of $100 \mathrm{Kg} /$ Hour

\begin{abstract}
The planned corn cormer is intended to destroy dry corn humps into small particles measuring 2 mm or smaller using a shaft, knife, bearing, pulley and diesel motor as a driving mechanism. In the planning of the corncob crusher the planned capacity is $100 \mathrm{~kg} /$ hour. With the intention of utilizing corn humps into additional feed for cattle and goat feed with a fast process. In the design of corn hump crusher has a main construction consisting of a mechanism to destroy corn cobs which work rotary by using a shaft made of S35S-D material with length of $510 \mathrm{~mm}$, diameter of 50 $\mathrm{mm}$ and crusher blade made of $S 35 \mathrm{C}$ with a length of $100 \mathrm{~mm}$, thickness of blade $5 \mathrm{~mm}$, force of destruction of corn cobs $108 \mathrm{~kg}$ and braking mechanism used by motor diesel with shaft rotation of $2000 \mathrm{rpm}$. While the motor power is planned to move the corn cormer crushing machine by $16 \mathrm{Pk}$. From the calculation results, the total power for the driving motor is $10.2 \mathrm{kw}$ and for the safety of the diesel motor it is planned to be $11.936 \mathrm{kw}=16 \mathrm{Pk}$ with $2000 \mathrm{rpm}$ rotation. From the results
\end{abstract}




\section{Published Maret 2019 \\ Jurnal Rekayasa Material, Manufaktur dan Energi http://jurnal.umsu.ac.id/index.php/RMME}

obtained, it can be concluded that in designing the engine the designer can determine the appropriate components for use in corn hull crusher and can calculate each component.

Keywords: corn hump, animal feed, cattle and goats

\section{PENDAHULUAN}

Perancangan atau merancang adalah sebuah proses, dan merupakan suatu bentuk asas menjadi semacam landasan pemikiran bagi perancang dalam menentukan gagasan rancangannya, juga sebagai pedoman dan pengarah bagi proses merancang. Seiring perkembangan zaman, daya fikir manusia akan inovasi teknologi semakin berkembang khususnya di bidang peternakan, dari hasil survai lapangan, selama ini masyarakat Desa Kacaribu Kabupaten Karo mengolah jagung hanya sebatas untuk mengambil bijinya saja dengan memanfaatkan mesin pemimpil jagung yang sudah ada, dimana setelah proses ini jagung masih meninggalkan sisa berupa bonggol jagung yang selama ini hanya dibuang atau dibakar, karena peternak di Desa Kacaribu kesulitan untuk mengolah bonggol jagung tersebut menjadi pakan ternak mereka. Bonggol jagung berbentuk batang berukuran cukup besar, sehingga tidak dapat dikonsumsi ternak jika diberikan langsung, oleh karena itu untuk memberikannya perlu dihancurkan terlebih dahulu. Adapun cara sederhana untuk menghancurkan bonggol jagung tersebut dengan cara mencacah mengunakan pisau tidak begitu efektif dan efisien karena prosesnya memakan waktu yang lama, membutuhkan tenaga yang lebih banyak dan hasilnya pun juga tidak maksimal. Untuk membantu kebutuhan akan pakan ternak sapi yang cukup tinggi, maka penulis tertarik untuk melakukan rancang bangun sebuah alat yaitu "Mesin Penghancur Bonggol Jagung". Sebagai hasil akhir, diharapkan mesin ini dapat dimanfaatkan oleh masyarakat peternak sapi di Desa Kacaribu untuk menghasilkan butiran bonggol jagung sebagai campuran pakan ternak mereka.

\section{Tujuan}

\section{Tujuan umum}

Tujuan umum dari pembahasan ini, yang merupakan kegiatan tugas akhir adalah melakukan Perancangan Mesin Penghancur Bonggol Jangung Untuk Pakan Ternak Sapi dan Kambing Kapasitas 100 kg/jam.

\section{Tujuan khusus}

Adapun tujuan khusus dari perancangan dengan pembahasan yang lebih rinci yaitu:

1 Menentukan karakteristik bonggol jagung.

2 Merancang mekanisme dan konstruksi mesin penghncur bonggol jagung untuk pakan ternak sapi dan kambing kapasitas $100 \mathrm{~kg} / \mathrm{jam}$.

3 Perhitungan komponen mesin (poros, puli, sabuk, bantalan).

Menghitung energi atau daya mesin penghancur bonggol jagung untuk pakan ternak sapi dan kambing kapasitas $100 \mathrm{~kg} / \mathrm{jam}$. 


\section{Published Maret 2019 \\ Jurnal Rekayasa Material, Manufaktur dan Energi http://jurnal.umsu.ac.id/index.php/RMME}

\section{METODE PENELITIAN}

\section{Tempat dan Waktu}

1. Tempat perancangan dan pembuatan mesin dan kegiatan uji cob dilaksanakan di Desa Kacaribu Kabupaten Karo.

2. Waktu perancangan dilaksanakan sejak tanggal pengesahan usulan oleh pengelola Program Studi Teknik Mesin sampai dinyatakan selesai, diperkirakan selama enam bulan.

\section{Bahan Dan Gambar Konstruksi Mesin}

Bahan bonggol jagung

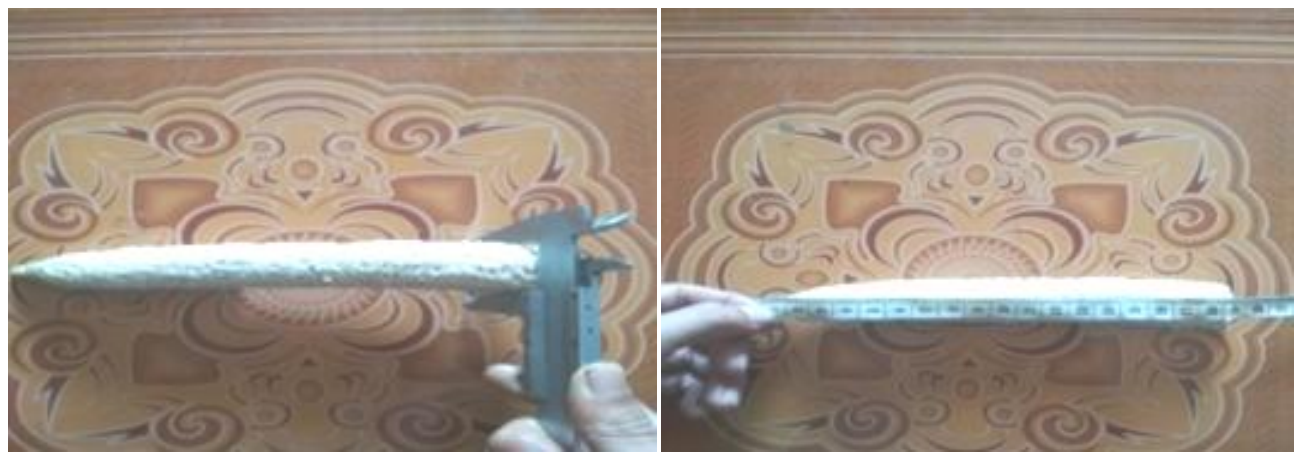

Gambar 1. Bonggol jagung

1. Karakteristik bonggol jagung
a. jenis bonggol jagung : kering
b. panjang rata-rata $: 230(\mathrm{~mm})$
c. diameter rata-rata $: 20(\mathrm{~mm})$
d. Sipatnya : Keras

\section{Konstruksi Mesin Pengahancur Bonggol Jagung}
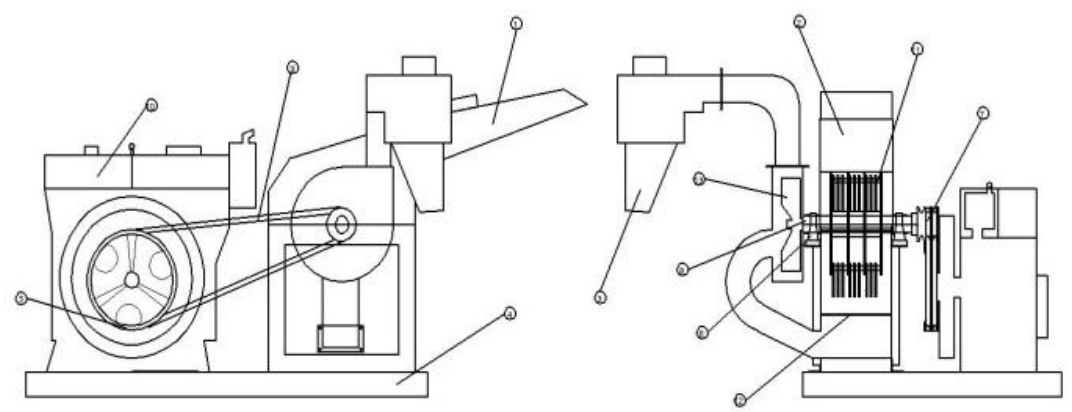

Gambar 2. Konstruksi Mesin Penghancur bonggol jagung

\section{Keterangn :}

1. Saluran masuk/corong, BerfungsiSebagai tempat penampungan atau tempat masuknya bonggol jagung yang akan dihancurkan. 


\section{Published Maret 2019 \\ Jurnal Rekayasa Material, Manufaktur dan Energi http://jurnal.umsu.ac.id/index.php/RMME}

2. Bodi mesin, Sebagai ruang atau tempat proses penghancuran bonggol jagung yang akan dihancurkan.

3. Saluran Keluar, Sebagai tempat untuk keluarnya bonggol jagung yang sudah hancur.

4. Rangka Mesin, Sebagai tempat dudukan mesin dan komponen-komponen lainya.

5. Puli Poros Penggerak, Berfungsi untuk meneruskan putaran poros motor

6. Bantalan Atas Poros, Sebagai membatasi gerak relatif poros bagian atas supaya bergerak pada arah yang diinginkan

7. Puli yang digerakkan, Berfungsi untuk memutar poros pisau penghancur

8. Poros Pisau yang digerakkan, Sebagai tempat dudukan Pisau pengha ncur.

9. Sabuk, Sebagai menghubungkan secara mekanis dua poros yang berputar.

10.Motor Penggerak, Sebagai penggerak utama dalam suatu mesin tersebut.

11.Pisau penghancur, Berfungsi sebagai penghancur bonggol jagung

12. Saringan, Berfungsi Sebagai penyaring bonggol jagung yang sudah hancur.

13. Kipas Penghisap, Sebagai alat bantu untuk menghisap butiran bonggol jagung yang sudah dihancurkan.

\section{Mekanisme cara Kerja Mesin Penghancur Bonggol Jagung}

Mekanisme cara kerja mesin penghancur bonggol jagung kering untuk pakan ternak sapi dirancang dan direncanakan sesuai dengan kebutuhan dan memenuhi fungsinya.

Adapun prinsip kerjanya, yaitu : bahan baku yang dimasukkan ke dalam mesin selanjutnya akan dibawa oleh sebuah pelat ke bagian penghancuran. Setelah bahan baku dihancurkan, lantas kemudian bahan pun akan

dipotong dengan kecepatan yang sangat tinggi sehingga menjadi tepung. Proses ini juga menimbulkan tekanan udara di dalam akan mengalir keluar. Dengan kata lain bahan baku yang berupa tepung akan terbang keluar melewati saringan. Bahan yang masih berukuran besar akan diproses kembali hingga berbentuk tepung halus.

\section{Metode Perancangan}

Rancangan mesin dilakukan terdiri dari beberapa tahapan pekerjan, mulai dari perancangan hingga perhitungan ukuran komponen-komponen permesinan. Setelah itu pembuatan konstruksi permesinan yang mempunyai rincian tahapan-tahapan sebagai berikut :

a. Persiapan

- Menetapkan Karakteristik dari bonggol jagung

- Menetapkan komponen mesin dan jenis bahan

b. Pelaksanaan

- Menentukan gaya dan putaran

- Perhitungan elemen konstruksi mesin

\section{Menetapkan Karakteristik dari bonggol jagung}

Bahan yang digunakan dalam metode ini adalah dari jenis bonggol jagung.

- Jenis Bonggol jagung :P 29 (Pioner)

- Panjang : $23 \mathrm{~cm}$

- Diameter $\quad: 2 \mathrm{~cm}$

\section{Menetapkan- komponen mesin dan jenis bahan}

Dalam perancangan mesin ini terlebih dahulu mengidentifikasi komponen yang mendukung dalam pembuatan mesin. 


\section{Published Maret 2019 \\ Jurnal Rekayasa Material, Manufaktur dan Energi http://jurnal.umsu.ac.id/index.php/RMME}

\section{Menentukan gaya dan putaran}

1. Menentukan Gaya

Dengan mengetahui gaya yang bekerja pada bonggol jgung, maka akan didapat besarnya gaya pada mesin dan dapat mengetahui gaya yang dibutuhkan untuk menghancurkan bonggol jagung tersebut. Atau terlebih dahulu mentukan gaya pencacahan yang bekerja pada bonggol jagung, kemudian dengan mengasumsikan berat bonggol jagung yang dihancurkan dalam waktu yang bersmaan.

2. Putaran Untuk kapasitas

Untuk mesin pengancur bonggol jagung dengan kapasitas yang ditentukan adalah seberat 100 $\mathrm{kg} / \mathrm{jam}$, maka dapat dijelaskan seperti dibawah ini:

- Jumlah bonggo jagung untuk kapasitas yang ditentukan yaitu $100 \mathrm{~kg} / \mathrm{jam}$

- Pada perancangan ini, pisau penghancur dapat menghanurkan bonggol jagung seberat 1,66 kg dalam waktu 1 menit atau 60 detik, maka dalam waktu 1 jam atau 60 menit dapat memenuhi kapasitas yang ditentukan yaitu $100 \mathrm{~kg} / \mathrm{jam}$.

- Pada putaran yang digunakan untuk memecahkan bonggol jagung dapat dilakukan dengan cara mengetahui putaran pada motor pengerak (donghay)

- Putaran motor pengerak yang direncanakan adalah 2000 rpm, ukuran puli yang dipasang pada motor pengerak adalah 12 inci sedangkan untuk puli yang digerakkan adalah 4 inci maka dapat diperoleh putaranya adalah $6000 \mathrm{rpm}$ untuk melakukan pencacahan bonggol jagung dengan kapasitas $100 \mathrm{~kg} / \mathrm{jam}$ yang ditentukan.

Secara umum langkah - langkah yang dilakukan dalam pelaksanaan penelitian ini dapat dilihat dalam diagram alir berikut:

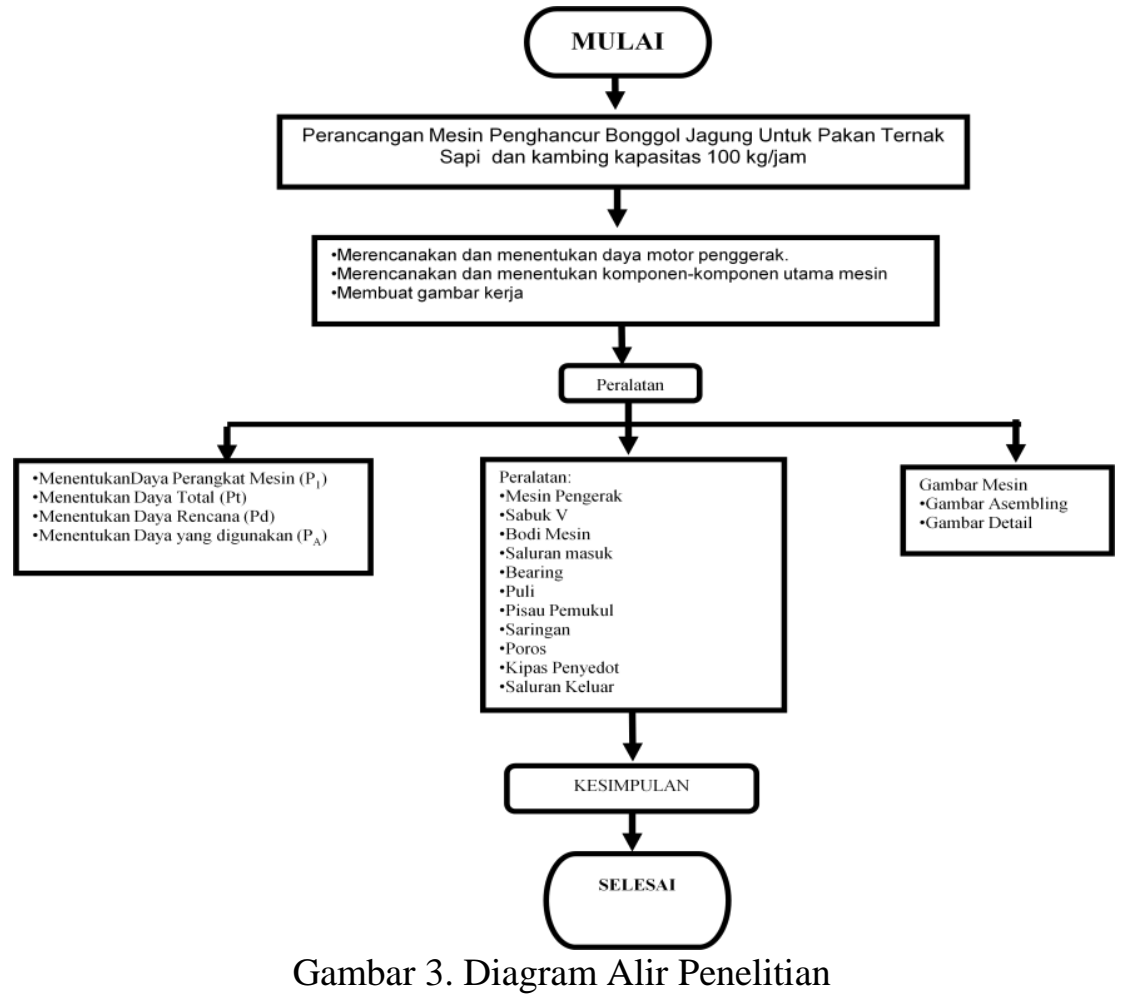

Copyright ${ }^{\odot} 2019$ Jurnal Rekayasa Material, Manufaktur dan Energi. This is an open acces article under the CC-BY-SA lisence (https://creativecommons.org/licenses/by-sa/4.0/). 


\section{Published Maret 2019 \\ Jurnal Rekayasa Material, Manufaktur dan Energi http://jurnal.umsu.ac.id/index.php/RMME}

HASIL DAN PEMBAHASAN

\section{Karakteristik Bonggol Jagung}

Disini kita akan membahan khusus untuk bonggol jagung yang sudah tua ataupun kering dimana bonggol jagung ini akan dihancurkan dengan mesin yang dirancang tujuannya bonngol jagung akan dijadikan sebaga pakan tambahan ternak sapi dan kambing.
Jenis jagung
: P29
sifat
: Keras
Panjang
: $23 \mathrm{Cm}$
Diameter
: $2 \mathrm{Cm}$

Berikut adalah gambar bonggol jagung sebelum dan sesudah dihancurkan:

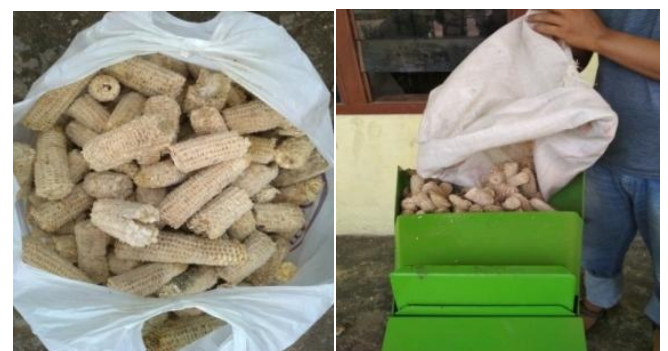

Gambar. 4. Bonggol jagung kering yang dihancurkan

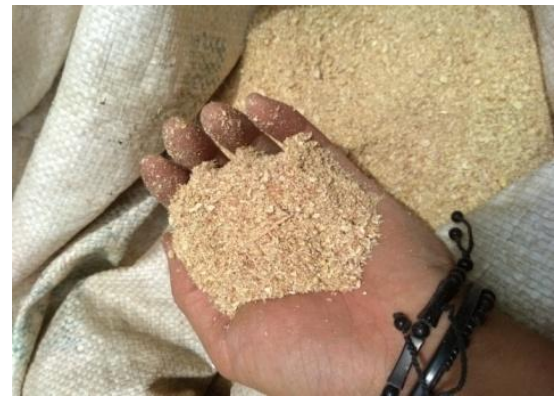

Gambar.5. Hasil bonggol jagung yang sudah hancur.

Menentukan komponen dan pemilihan bahan yang sesuai untuk elemen mesin mesin penghancur bonggol jagung

Pada mesin penghancur bonggol jagung ini terdapat dua bagian komponen yaitu:

Komponen utama mesin penghancur bonggol jagung

Tabel 1. Komponen utama

\begin{tabular}{cllc}
\hline No & Nama Komponen & Bahan & Jumlah \\
\hline 1 & Saluran masuk & Plat S35C & 1 \\
2 & Bodi tempat penghancuran & Plat S35C & 1 \\
3 & Kipas penghisap & S35C & 1 \\
4 & Dudukan pisau & S40C & 1 \\
5 & As pisau & Besi baja biasa & 4 \\
6 & Pisau penghancur & S40C & 36 \\
\hline
\end{tabular}

Copyright ${ }^{\odot} 2019$ Jurnal Rekayasa Material, Manufaktur dan Energi. This is an open acces article under the CC-BY-SA lisence (https://creativecommons.org/licenses/by-sa/4.0/). 


\section{Published Maret 2019 \\ Jurnal Rekayasa Material, Manufaktur dan Energi http://jurnal.umsu.ac.id/index.php/RMME}

\begin{tabular}{cllc}
\hline No & Nama Komponen & Bahan & Jumlah \\
\hline 7 & Poros yang digerakkan & S40C & 1 \\
8 & Saluran keluar & Plat S35C & 1 \\
9 & Rangka & Besi propi“U” & 1 \\
\hline
\end{tabular}

Tabel 2. Komponen pendukug

\begin{tabular}{cllcc}
\hline NO & Nama komponen & Jenis/bahan & Gambar & Jumlah \\
\hline 1 & $\begin{array}{l}\text { Sabuk } \\
\text { Bantalan }\end{array}$ & $\begin{array}{l}\text { Standart "V" } \\
\text { Satandart }\end{array}$ & 1 \\
3 & Saringan & Plat baja & 1 \\
4 & Puli & Besi cor & & 2 \\
5 & Motor pengerak & 16 Pk 2000 rpm & 1 \\
6 & Baut dan mur & Standart & & berbagai \\
& & & ukuran
\end{tabular}

\section{Menentukan Gaya dan Putaran}

Menentukan gaya potong yang terjadi pada pisau penghancur tentunya harus mengetahui teganggan geser pada bonggol jagung. Perhitungan untuk menentukan gaya potong yang dibutuhkan untuk melakukan penghancuran terhadap bonggol jagung. Gaya $F$ pada poros penghancur bonggol jagung adalah besar tegangan geser bahan bonggol jagung dikali dengan luas penampang bagian yang potong atau yang dihancurkan, dimana digunakan rumus sebagai berikut.

$$
\mathrm{FS}=\operatorname{tg} \cdot \mathrm{A}
$$

Dimana :

FS = gaya yang dibutuhkan untuk melakukan penghancuran terhadap bonggol jagung $(\mathrm{kg})$

$\mathrm{Tg}=$ tegangan geser bahan bonggol jagung.

Berhubung dengan tegangan geser bonggol jagung sangat sulit sangat sulit untuk ditentukan, maka penulis melakukan asumsi atau anggapan bahwa tegagan geser bonggol jagung diasumsikan sama dengan 10\% dari tegangan tarik kayu yang paling lunak. Dimana tegangan tarik kayu yang paling lunak (golongan IV) adalah $\mathrm{rt}=50 \mathrm{~kg} / \mathrm{cm}$ ), (PDEC,Bandung, 1982, Pedoman Konstuksi Kayu Edisi, 1 Bandung).

Jadi tegangan geser bonggol jagung adalah :

$$
\mathrm{Tg}=10 \% \times 50(\mathrm{~kg} / \mathrm{cm})=5(\mathrm{~kg} / \mathrm{cm}) \quad=50.000(\mathrm{~kg} / \mathrm{cm})
$$

$\mathrm{A}=$ luas penampang bonggol jagung yang mengalami penghancuran di asumsikan luas penampang yang mengalami penghancuran adalah jumlah mata pisau dikali dengan luas penampang pisau yang melakukan penghancuran 


\section{Published Maret 2019 \\ Jurnal Rekayasa Material, Manufaktur dan Energi http://jurnal.umsu.ac.id/index.php/RMME}

pada saat yang sama.

- jumlah mata pisau pada saat melakukn penghancuran pada saat yang sama adalah 36 (tiga puluh enam) buah penghancur.

- Luas penampang mata pisau yang melakukan penghancur adalah $36 \mathrm{x} \quad(6 \mathrm{x} 100)=21600$ $(\mathrm{mm})=0,0216\left(\mathrm{~m}^{2}\right)$

Maka gaya yang timbul oleh peroses penghancuran bonggol jagung, adalah:

$$
\mathrm{F}=(50.000) \times 0,0216
$$

$=108(\mathrm{~kg})$

Untuk menentukan putaran poros pengerak harus dilakukan beberapa pertimbangan diantaranya adalah sebagai brikut:

- Analisa Kapasitas Mesin yang direncanakn.

Kapaaitas mesin penghancur bonggol jagung telah ditentukan sebesar 100 (kg/jam).

- Massa $1(\mathrm{~kg})$ bonggol jagung \pm 30 buah bonggol jagung

- Untuk kapasitas $100 \mathrm{~kg} / \mathrm{jam}$, maka untuk tiap jamnya mesin yang direncanakan harus mampu melakukan penghancuran sebanyak 10 x 30 buah bonggol jagung $\approx 3000$ buah bonggol jagung untuk setiap jam.

Untuk mesin pengancur bonggol jagung dengan kapasitas yang ditentukan adalah seberat $100 \mathrm{~kg} / \mathrm{jam}$, maka dapat dijelaskan seperti dibawah ini:

- Jumlah bonggo jagung untuk kapasitas yang ditentukan yaitu $100 \mathrm{~kg} / \mathrm{jam}$

- Pada perancangan ini, pisau penghancur dapat menghanurkan bonggol jagung seberat 1,66 $\mathrm{kg}$ dalam waktu 1 menit atau 60 detik, maka dalam waktu 1 jam atau 60 menit dapat memenuhi kapasitas yang ditentukan yaitu $100 \mathrm{~kg} / \mathrm{jam}$.

- Pada putaran yang digunakan untuk memecahkan bonggol jagung dapat dilakukan dengan cara mengetahui putaran pada motor pengerak (donghay)

- Putaran motor pengerak yang direncanakan adalah 2000 rpm, ukuran puli yang dipasang pada motor pengerak adalah 12 inci sedangkan untuk puli yang digerakkan adalah 4 inci maka dapat diperoleh putaranya adalah $6000 \mathrm{rpm}$ untuk melakukan pencacahan bonggol jagung dengan kapasitas $100 \mathrm{~kg} / \mathrm{jam}$ yang ditentukan.

\section{Menentukan daya motor pengerak yang dibutuhkan untuk melakukan penghancuran bonggol jagung}

1. Menentukan torsi pada poros pemutar pisau

Perhitungan torsi yang terjadi

$\mathrm{T}=$ torsi yang diakibatkan oleh penghancuran terhadap bonggol jagung (kg.m)

$\mathrm{T}=$ F.r

Di mana :

$\mathrm{F}=$ gaya pengancuran bonggol jagung pada sistem $108 \mathrm{~kg}$

$\mathrm{r}=$ jarak beban rata - rata kesumbu poros $300: 2=150=0,15 \mathrm{~m}$

Jadi torsi yang terjadi adalah

$\mathrm{T}=108 \times 0,15(\mathrm{~kg} \cdot \mathrm{m})$

$=16,2(\mathrm{~kg} \cdot \mathrm{m})$ 


\section{Published Maret 2019 \\ Jurnal Rekayasa Material, Manufaktur dan Energi http://jurnal.umsu.ac.id/index.php/RMME}

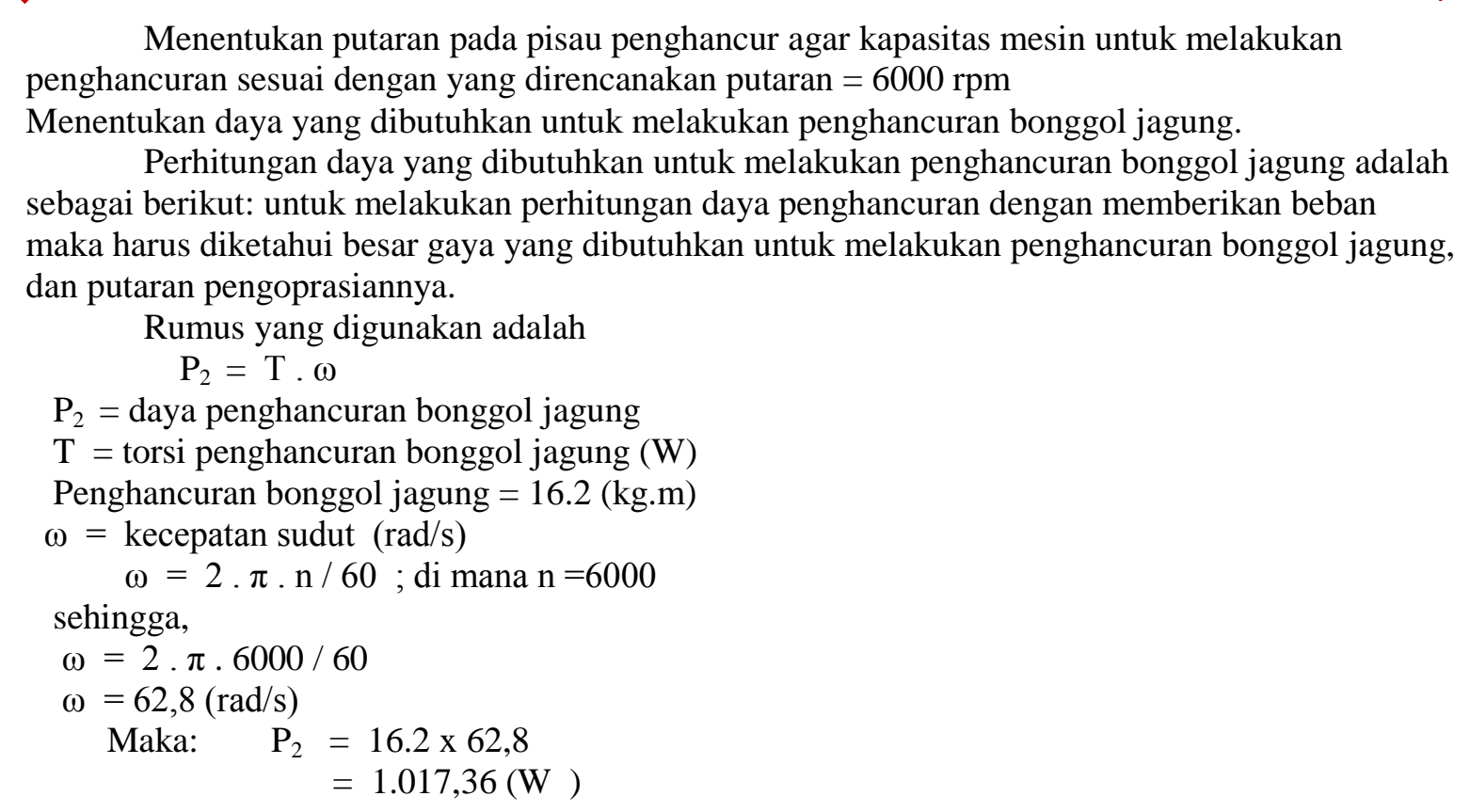

\section{Daya motor pengerak total $(\mathbf{P})$}

Dari torsi yang terjadi pada poros pisau maka akan dapat dicari daya yang dibutuhkan untuk menghancurkan bonggol jagung adalah

$$
\begin{aligned}
& P=\frac{2 \times \pi \times n \times \mathrm{T}}{60} \\
& \text { Di mana }: \mathrm{P} \quad=\text { daya motor }(\mathrm{kw}) \\
& \mathrm{n} \quad=\text { putaran rotor }(\mathrm{rpm}) \\
& \mathrm{T}=\operatorname{torsi}(\mathrm{Nm}) \\
& \mathrm{P}=P=\frac{2 \times \pi \times 6000 \times 16,2}{60} \\
& =10.173 .6 \mathrm{~W} \\
& =10,2(\mathrm{kw})
\end{aligned}
$$

Maka : 10,2 $(\mathrm{kw} \mathrm{x} \mathrm{1,341)}=13,7 \mathrm{hp}$

Dengan demikian daya motor adalah $13,7 \mathrm{hp}$ dengan motor yang di pasang pada mesin $16 \mathrm{Hp}=16$ Pk dengan putaran yang direncanakan $(2000 \mathrm{rpm}$.

\section{KESIMPULAN}

Setelah dilakukan pembahasan tentang perancangan mesin penghancur bonggol jagung kapasitas $100 \mathrm{~kg} / \mathrm{jam}$, dengan hasil yang dapat diterima sesuai dengan yang direncanakan yaitu: Daya motor pengerak

Daya yang dibutuhkan untuk menghancurkan bonggol jagung sebesar 10,2 (kw) dari parameter 1 $\mathrm{kw}=1,341 \mathrm{hp}$ maka didapat 13,7 hp dengan putaran $6000(\mathrm{rpm})$ Dengan demikian motor yang di pasang pada mesin $16 \mathrm{Hp}=16 \mathrm{Pk}$. 


\section{Published Maret 2019 \\ Jurnal Rekayasa Material, Manufaktur dan Energi http://jurnal.umsu.ac.id/index.php/RMME}

\section{DAFTAR PUSTAKA}

[1] Hanoto, 1981, Mekanika Teknik, PEDC Bandung.

[2] Hartanto, Sugiarto, dan Sato Takeshi. 1992. Menggambar Mesin Menurut Standar ISO. Jakarta: PT. Pradnya Paramita.

[3] Joseph E. Shigley, Larry D. Mitchell, Ir. Gandhi Harahap M.Eng, 1984, Perencanaan Teknik Mesin, Edisi Keempat, Jilid 2, Penerbit Erlangga, Jakarta.

[4] Khurmi, R.S dan Gupta, J.K, 1990, A Tex Book of Machine Design, Eurasia, Publishing ,New Delhi, India.

[5] Sularso, Kiyokatsu Suga, 1997, Dasar Perencanaan dan Pemilihan Elemen Mesin, PT. Paradnya Paramita, Jakarta.

[6] Sugiarto, Sato Takesi, 1996, Gambar Mesin, PT. Paradnya Paramita, Jakarta 